\title{
Pengembangan model bimbingan kelompok berbasis islami untuk meningkatkan kecerdasan sosial siswa SMK
}

\author{
Riki Maulana \\ Bimbingan dan Konseling, IKIP-PGRI Pontianak \\ Email: rikimaulana556@gmail.com
}

(Diterima: 05-April-2016; di revisi: 10-Juni-2016; dipublikasikan: 28-Juni-2016)

\begin{abstract}
The research is aimed to 1) know the implementation of group counseling in private vocational school in Semarang. 2) know the social intelligence condition in SMK Roudiotus Saidiyyah Semarang. 3) Produce Islamic teaching based group counseling model to increase social intelligence of students in Roudiotus Saidiyyah Semarang. 4) ehther or not the implementation of the islamic teaching based group counseling model effectiveness in increasing social intelligence of the students in Roudiotus Saidiyyah Semarang. The research method used is Research and Development (R \& D) method. The data analysis technique used are both qualitative and quantitative. The findings were the Islamic teaching based group counseling model consists of rasional, vision and misson, objectives, the model content, the stages in Islamic teaching based group counseling model, role and function of the group leader, group member qualification, evaluation and follow up.
\end{abstract}

Keywords: Group counseling, Islam based, social intelligence.

Abstrak: Penelitian ini bertujuan (1) Mengetahui pelaksanaan bimbingan kelompok di SMK Swasta Kota Semarang. (2) Mengetahui kondisi kecerdasan sosial di SMK Roudlotus Saidiyyah Semarang. (3) Menghasilkan model bimbingan kelompok berbasis Ajaran Islam untuk meningkatkan kecerdasan sosial siswa SMK Roudlotus Saidiyyah Semarang. (4) Mengetahui keefektifan pelaksanaan bimbingan kelompok berbasis Ajaran Islam untuk meningkatkan kecerdasan sosial SMK Roudlotus Saidiyyah Semarang. Metode dalam penelitian ini menggunakan research and development $(\mathrm{R} \& \mathrm{D})$. Teknik analisis data menggunakan teknik kualitatif dan kuantitatif. Hasil dari penelitian ini adalah model bimbingan kelompok berbasis Islami yang terdiri dari rasional, visi dan misi, tujuan, isi model, tahapan bimbingan kelompok berbasis Islami, peran dan fungsi pemimpin kelompok, kualifikasi anggota kelompok, evaluasi dan tindak lanjut.

Kata kunci: Bimbingan kelompok, islami, kecerdasan sosial.

Copyright (C) 2016 Universitas Negeri Makassar. This is an open access article under the CC BYNC-ND license (http://creativecommons.org/licenses/by-nc-nd/4.0/).

\section{PENDAHULUAN}

Kecerdasan sosial merupakan pencapaian kualitas manusia mengenai kesadaran diri dan penguasaan pengetahuan yang bukan hanya untuk keberhasilan dalam melakukan hubungan sosial, tetapi kecerdasan sosial digunakan untuk membuat kehidupan manusia menjadi lebih bermanfaat bagi lingkungan dan masyarakat sekitar. Kecerdasan sosial akan memberi ketajaman dan kejernihan dalam memandang masalah (Suyono, 2007: 22). Masalah akan 
diselesaikan dengan baik karena individu atau kelompok yang mempunyai kecerdasan sosial akan melihat suatu masalah dengan obyektif, dapat menilai suatu peristiwa secara adil dan terampil dalam mengatasi masalah sehingga tidak beresiko ke arah perilaku negatif.

Salah satu dampak dari rendahnya kecerdasan sosial pada diri seseorang adalah tawuran yang terjadi antar pelajar. Seperti yang terjadi di Bogor, Seorang pelajar kelas III SMK Bhakti Taruna Bogor tewas di lokasi setelah terkena sabetan celurit Siswa SMK YZA 1 yang menjadi lawan tawurannya. Korban adalah AR (17), warga Sindangsari, Kecamatan Bogor Timur, Kota Bogor. Korban meninggal dengan luka bekas sabetan celurit dan tusukan di bagian perut dan punggungnya (detik news: 04/12/2013). Dari peristiwa tersebut diasumsikan bahwa penyebabnya adalah rendahnya sikap empati, sikap prososial dan kurangnya pemahaman tentang pentingnya menjaga hubungan sosial.

Guna memperoleh kejelasan mengenai keadaan kecerdasan sosial siswa dan pelaksanaan bimbingan kelompok, maka dilakukan wawancara terhadap Guru Bimbingan dan Konseling (BK) di SMK Swasta yang ada di Kota Semarang tahun ajaran 2013/2014, diantaranya Guru BK SMK Teuku Umar, Guru BK SMK I Muhammadiyah, Guru BK SMK Perintis 29-01 dan Guru BK SMK Perintis 29-02. Dari hasil wawancara tersebut mengindikasikan bahwa sebagian siswa kurang memiliki rasa sosial terhadap sesama teman, hal ini ditunjukkan dengan siswa senang menertawai jika ada teman yang mendapat hukuman, sering mengejek teman yang memiliki kekurangan dan pernah terjadi keributan antar kelompok siswa. Selain itu, dari sisi pelaksanaan bimbingan kelompok sudah terprogram dan terlaksana di masing-masing sekolah. Namun, bimbingan kelompok masih jarang membahas tentang upaya meningkatkan kecerdasan sosial maupun yang bertema sosial. Bimbingan kelompok lebih menekankan siswa untuk berprestasi dan giat belajar, serta lebih mengarah kepada konseling kelompok yakni siswa yang mengikuti bimbingan kelompok adalah siswa yang nakal dan sering melanggar peraturan sekolah.

Kecerdasan sosial memiliki peran penting di dalam kehidupan seseorang karena dampak negatif dari kecerdasan yang rendah dapat merusak kualitas hidup seseorang. Merujuk berbagai fenomena yang terjadi, maka perlu adanya tindakan atau layanan yang dapat meningkatkan kecerdasan sosial. Pelaksanaan bimbingan dan konseling di sekolah khususnya bimbingan kelompok, dianggap cocok untuk meningkatkan kecerdasan sosial karena di dalamnya terdapat sekelompok individu yang saling berinteraksi dan memunculkan dinamika di dalam kelompok. Hal ini sesuai menurut Prayitno (2004: 307) yaitu apabila konseling perorangan menunjukkan layanan kepada individu atau klien orang-perorangan, maka bimbingan dan konseling kelompok mengarahkan pada sekelompok individu. Dengan satu kali kegiatan bimbingan kelompok memberikan manfaat atau jasa kepada sejumlah orang.

Tindakan efektif harus sesegera mungkin perlu dilakukan dengan memadukan nilai-nilai ajaran Islam dalam layanan bimbingan kelompok untuk meningkatkan kecerdasan sosial dalam diri siswa. Maka dari itu peneliti berkeinginan untuk menciptakan layanan bimbingan kelompok melalui nuansa Islami yang akan dimanfaatkan sebagai bentuk pengembangan dalam memperkuat pencapaian manfaat layanan bimbingan kelompok dalam rangka meningkatkan kecerdasan sosial siswa. Landasan Agama merupakan landasan yang dapat memberikan pemahaman kepada konselor tentang dimensi keagamaan sebagai faktor yang memengaruhi terhadap perilaku individu. Landasan agama pada dasarnya ingin menetapkan klien sebagai makhluk Tuhan dengan segenap kemuliaannya menjadi fokus sentral upaya bimbingan dan konseling.

Menurut Gibson dan Marianne (2011: 275), istilah bimbingan kelompok mengacu pada aktivitas-aktivitas kelompok yang berfokus pada penyediaan informasi atau pengalaman lewat aktivitas kelompok yang terencana atau terorganisir. Pelaksanaan bimbingan kelompok merupakan suatu kegiatan kelompok yang dilakukan oleh sekelompok orang dengan memanfaatkan dinamika kelompok. Selain itu. Selanjutnya Wibowo (2005: 17) mengemukakan bahwa bimbingan kelompok merupakan suatu kegiatan kelompok dimana pimpinan kelompok menyediakan informasi-informasi dan mengarahkan diskusi agar anggota kelompok menjadi lebih sosial atau untuk membantu anggota-anggota kelompok untuk mencapai tujuan-tujuan bersama 
Dalam Islam, bimbingan dan konseling merupakan bentuk bantuan yang bertujuan pada kemaslahatan. Bimbingan dan konseling Islami diberikan sebagai alternatif bagi pemecahan masalah kemanusiaan dan sosial yang semakin kompleks. Faqih (Dahlan, 2009: 1) mengatakan bahwa Bimbingan dan Konseling Islami adalah proses pemberian bantuan terhadap individu agar mampu hidup selaras dengan ketentuan dan petunjuk Allah sehingga dapat mencapai kebahagiaan hidup di dunia dan akhirat.

Menurut Sutoyo (2009: 205) hakikat Bimbingan dan Konseling Islami ialah upaya membantu individu belajar mengembangkan fitrah-iman dan atau kembali kepada fitrah-iman dengan cara memberdayakan (empowering) fitrah-fitrah (jasmani, rohani, nafs, dan iman) agar fitrah-fitrah yang ada pada individu berkembang dan berfungsi dengan baik dan benar.

Bimbingan dan Konseling Islami juga diartikan sebagai proses pemberian bantuan terarah, kontinu dan sistematis kepada individu agar dapat mengembangkan potensi atau fitrah beragama yang dimilikinya secara optimal dengan cara menginternalisasikan nilai-nilai yang terkandung di dalam al-Qur'an dan Hadits Rasulullah ke dalam dirinya, sehingga ia dapat hidup selaras dan sesuai dengan tuntunan alQur'an dan Hadits (Amin, 2010: 23).

Merujuk kepada pengertian bimbingan kelompok secara umum dan pengertian bimbingan dan konseling Islami yang telah dijelaskan oleh beberapa ahli di atas, maka dapat dirumuskan bahwa bimbingan kelompok berbasis Islami adalah proses pemberian bantuan yang dilakukan oleh seorang ahli kepada individu melalui suasana kelompok dengan mengintegrasikan nilai-nilai yang terkandung di dalam ajaran Islam yang memungkinkan setiap anggota untuk belajar berpartisipasi aktif dan berbagi pengalaman dalam upaya pengembangan wawasan, sikap dan atau keterampilan yang diperlukan untuk mencegah timbulnya masalah atau pengembangan pribadi dalam rangka membantu individu hidup selaras dengan ketentuan dan petunjuk Allah sehingga dapat mencapai kebahagiaan hidup di dunia dan akhirat.

Rumusan masalah dalam penelitian adalah: (1) Bagaimana pelaksanaan bimbingan kelompok di SMK Swasta Kota Semarang? (2) Bagaimana kondisi kecerdasan sosial siswa SMK
Roudlotus Saidiyyah Semarang? (3) Bagaimana model bimbingan kelompok berbasis Ajaran Islam untuk meningkatkan kecerdasan sosial siswa di SMK Roudlotus Saidiyyah Semarang? (4) Bagaimana keefektifan model layanan bimbingan kelompok berbasis Ajaran Islam dalam meningkatkan kecerdasan sosial siswa SMK Roudlotus Saidiyyah Semarang?

Tujuan penelitian (1) Mengetahui pelaksanaan bimbingan kelompok di SMK Swasta Kota Semarang. (2) Mengetahui kondisi kecerdasan sosial di SMK Roudlotus Saidiyyah Semarang. (3) Menghasilkan model bimbingan kelompok berbasis Ajaran Islam untuk meningkatkan kecerdasan sosial siswa SMK Roudlotus Saidiyyah Semarang. (4) Mengetahui keefektifan pelaksanaan bimbingan kelompok berbasis Ajaran Islam untuk meningkatkan kecerdasan sosial SMK Roudlotus Saidiyyah Semarang.

\section{METODE}

Metode penelitian ini menggunakan pendekatan penelitian dan pengembangan (research and development). Metode penelitian dan pengambangan merupakan metode yang digunakan untuk menghasilkan produk tertentu dan menguji keefektifan model tersebut. Dalam konteks pendidikan, maka produk yang dimaksud adalah berkaitan dengan komponen sistem pendidikan. Produk pendidikan yang dapat dihasilkan melalui pendekatan penelitian dan pengembangan adalah buku teks, film intsruksional, program komputer, metode mengajar dan berbagai program pendidikan lainnya.

Produk yang dihasilkan dalam penelitian adalah sebuah model bimbingan kelompok berbasis Islami untuk meningkatkan kecerdasan sosial siswa. kerangka isi dan komponen model disusun berdasarkan kajian teoritis bimbingan kelompok, nilai-nilai Islami, penelitian terdahulu dan kondisi faktual pelaksanaan bimbingan kelompok di SMK swasta Kota Semarang. Adapun tahapan bimbingan kelompok berbasis Islami adalah studi pendahuluan, merumuskan model hipotetik, uji kelayakan model hipotetik, perbaikan model hipotetik menjadi model awal, uji terbatas, dan model akhir.

Desain uji coba dalam penelitian pengembangan ini dilakukan untuk menghasilkan sebuah model bimbingan kelompok berbasis 
Islami yang rasional, aplikatif dan teruji. Uji ahli dilakukan dengan melibatkan tiga orang pakar Bimbingan dan Konseling untuk menilai model hipotetik agar menjadi sebuah model yang secara rasional mampu meningkatkan kecerdasan sosial. Uji praktisi dilakukan dengan melibatkan 10 orang guru Bimbingan dan Konseling untuk memvalidasi model hipotetik agar menjadi model yang dapat digunakan dalam pelaksanaannya. Sedangkan uji coba terbatas dilakukan dengan desain true eksperimental: pretest-postest control group design.

Setelah layanan dilaksanakan maka peneliti akan melakukan tes untuk mengukur kecerdasan sosial siswa dengan model bimbingan kelompok yang dirumuskan. Pengujian hipotesis digunakan analisis data kuantitatif dengan teknik statistik non-parametris, yaitu menggunakan Independen Sampel $T$ Test. Untuk menguji hipotesis dicari dengan cara mencari perbedaan hasil kelompok eksperimen dan kelompok kontrol, antara skor pretest dan posttest. Dalam perhitungan Independen Sampel $T$ Test akan digunakan bantuan software SPSS seri 21.00

\section{HASIL DAN PEMBAHASAN}

Bimbingan kelompok sudah dilaksanakan di SMK Swasta Kota Semarang dengan melewati 4 tahapan, yakni tahap pembentukan, tahap peralihan, tahap kegiatan, dan tahap pengakhiran. Namun, dalam pelaksanaan yang dilakukan belum efektif dan belum memberikan hasil yang optimal. Masih ada beberapa kekurangan seperti kurangnya menggunakan media dan teknik, belum dilakukan analisis kebutuhan siswa dalam merekrut anggota kelompok, kurangnya persiapan sebelum melaksanakan bimbingan dan kelompok dan belum menggunakan pendekatan Islami.

Gambaran tentang kondisi kecerdasan sosial siswa SMK Roudlotus Saidiyyah Semarang diperoleh dari hasil penyebaran skala kecerdasan sosial terhadap 60 siswa. Peneliti memberikan instrumen berupa skala kecerdasan sosial kepada masing-masing siswa. Instrumen terdiri dari dari 31 item pernyataan yang digunakan untuk mengukur tingkat kecerdasan sosial siswa SMK Roudlotus Saidiyyah Semarang. Semua siswa mengerjakannya sesuai dengan petunjuk yang dijelaskan oleh peneliti.

Tabel 1. Kondisi Kecerdasan Sosial Berdasarkan Jumlah Siswa Perindikator

\begin{tabular}{|c|c|c|c|c|c|c|}
\hline \multirow{2}{*}{$\begin{array}{c}\text { Indikator } \\
\text { kecerdasan } \\
\text { sosial }\end{array}$} & \multirow{2}{*}{$\begin{array}{c}\text { Frekuensi } \\
\%\end{array}$} & \multicolumn{4}{|c|}{ Kategori } & \multirow[b]{2}{*}{$\sum$} \\
\hline & & ST & $\mathbf{T}$ & $\mathbf{R}$ & SR & \\
\hline \multirow{2}{*}{$\begin{array}{c}\text { Social } \\
\text { sensitivity }\end{array}$} & Frekuensi & 4 & 31 & 20 & 5 & 60 \\
\hline & $\%$ & 6,67 & 51,67 & 33,33 & 8,3 & 100 \\
\hline \multirow{2}{*}{$\begin{array}{l}\text { Social } \\
\text { insight }\end{array}$} & Frekuensi & 8 & 4 & 47 & 1 & 60 \\
\hline & $\%$ & 13,33 & 6,67 & 78,33 & 1,67 & 100 \\
\hline \multirow{2}{*}{$\begin{array}{c}\text { Social } \\
\text { comunication }\end{array}$} & Frekuensi & 6 & 45 & 9 & 0 & 60 \\
\hline & $\%$ & 10 & 75 & 15 & 0 & 100 \\
\hline \multirow{2}{*}{ Rata-rata } & Frekuensi & 6 & 26,67 & 25,33 & 2 & 60 \\
\hline & $\%$ & 10 & 44,45 & 42,22 & $\mathbf{3 , 3 3}$ & 100 \\
\hline
\end{tabular}

Tabel di atas menunjukan bahwa frekuensi/jumlah tingkat kecerdasan sosialsiswa pada kategori sangat tinggi sebanyak 6 siswa (10 $\%)$, kategori tinggi sebanyak 27 siswa $(44,45 \%)$, kategori rendah 25 siswa $(42,22 \%)$, dan ada dua siswa $(3,33 \%)$ yang termasuk kategori sangat rendah. Data ini memperkuat asumsi dasar bahwasanya tingkat kecerdasan sosial siswa SMK Roudlotus Saidiyyah Semarang tergolong rendah. Artinya data hasil skala kecerdasan sosial tersebut selaras dengan permasalahan yang selama ini terjadi pada siswa.
Setelah diberikan layanan bimbingan kelompok berbasis Islami, terdapat peningkatan kecerdasan sosial oleh masing-masing siswa. Secara kuantitatif meningkatnya tingkat kecerdasan sosial siswa bisa dilihat dari perbandingan nilai evaluasi awal dan evaluasi akhir yang diperoleh masing-masing anggota kelompok. Berikut rincian perolehan skor evaluasi awal dan evaluasi akhir anggota kelompok pada semua indikator: 
Tabel 2 Perolehan Skor Pretest dan Posttest Kelompok Eksperimen

\begin{tabular}{|c|c|c|c|c|c|c|c|}
\hline No. & $\begin{array}{c}\text { Anggota } \\
\text { Kelompok }\end{array}$ & $\begin{array}{c}\text { Frekuensi } \\
\%\end{array}$ & Pretest & Kategori & Postest & Kategori & Perubahan \\
\hline 1 & Tom & $\begin{array}{l}\mathrm{F} \\
\%\end{array}$ & $\begin{array}{c}72 \\
58,06\end{array}$ & $\mathrm{R}$ & $\begin{array}{c}85 \\
68,55\end{array}$ & $\mathrm{~T}$ & $\begin{array}{c}13 \\
10,49\end{array}$ \\
\hline 2 & Zak & $\begin{array}{l}\mathrm{F} \\
\%\end{array}$ & $\begin{array}{c}113 \\
91,13\end{array}$ & $\mathrm{ST}$ & $\begin{array}{c}115 \\
92,74\end{array}$ & ST & $\begin{array}{c}2 \\
1,61\end{array}$ \\
\hline 3 & Dav & $\begin{array}{l}\mathrm{F} \\
\%\end{array}$ & $\begin{array}{c}70 \\
56,45\end{array}$ & $\mathrm{R}$ & $\begin{array}{c}88 \\
70,97\end{array}$ & $\mathrm{~T}$ & $\begin{array}{c}18 \\
14,52\end{array}$ \\
\hline 4 & Nang & $\begin{array}{l}\mathrm{F} \\
\%\end{array}$ & $\begin{array}{c}104 \\
83,87\end{array}$ & ST & $\begin{array}{c}111 \\
89,52\end{array}$ & ST & $\begin{array}{c}7 \\
5,66\end{array}$ \\
\hline 5 & Mat & $\begin{array}{l}\mathrm{F} \\
\%\end{array}$ & $\begin{array}{c}76 \\
61,29\end{array}$ & $\mathrm{R}$ & $\begin{array}{c}88 \\
70,97\end{array}$ & $\mathrm{~T}$ & $\begin{array}{c}12 \\
9,68\end{array}$ \\
\hline 6 & Dis & $\begin{array}{l}\mathrm{F} \\
\%\end{array}$ & $\begin{array}{c}81 \\
65,32\end{array}$ & $\mathrm{~T}$ & $\begin{array}{c}101 \\
81,45\end{array}$ & $\mathrm{~T}$ & $\begin{array}{c}20 \\
16,13\end{array}$ \\
\hline 7 & Ard & $\begin{array}{l}\mathrm{F} \\
\%\end{array}$ & $\begin{array}{c}71 \\
51,76 \\
\end{array}$ & $\mathrm{R}$ & $\begin{array}{c}91 \\
73,39\end{array}$ & $\mathrm{~T}$ & $\begin{array}{c}20 \\
21,63\end{array}$ \\
\hline 8 & Din & $\begin{array}{l}\mathrm{F} \\
\%\end{array}$ & $\begin{array}{c}64 \\
51,61\end{array}$ & $\mathrm{R}$ & $\begin{array}{c}92 \\
74,19\end{array}$ & $\mathrm{~T}$ & $\begin{array}{c}28 \\
22,58\end{array}$ \\
\hline 9 & Tang & $\begin{array}{l}\mathrm{F} \\
\%\end{array}$ & $\begin{array}{c}75 \\
60,48\end{array}$ & $\mathrm{R}$ & $\begin{array}{c}87 \\
70,16\end{array}$ & $\mathrm{~T}$ & $\begin{array}{c}12 \\
9,68\end{array}$ \\
\hline 10 & Nik & $\begin{array}{l}\mathrm{F} \\
\%\end{array}$ & $\begin{array}{c}80 \\
64,52\end{array}$ & $\mathrm{~T}$ & $\begin{array}{c}95 \\
76,61\end{array}$ & $\mathrm{~T}$ & $\begin{array}{c}15 \\
12,09\end{array}$ \\
\hline & Rata-rata & $\begin{array}{l}\mathbf{F} \\
\%\end{array}$ & $\begin{array}{c}80,6 \\
65,00\end{array}$ & $\mathbf{T}$ & $\begin{array}{c}95,3 \\
76,85\end{array}$ & $\mathbf{T}$ & $\begin{array}{c}14,7 \\
11,85\end{array}$ \\
\hline
\end{tabular}

Berdasarkan tabel di atas terlihat bahwasanya kecerdasan sosial pada semua siswa yang menjadi anggota kelompok mengalami peningkatan (nilai evaluasi awal lebih rendah dari nilai evaluasi akhir). Ketercapaian hasil tersebut karena layanan bimbingan kelompok berbasis Islami dilaksanakan secara profesional sesuai dengan prosedur yang telah direncanakan, walaupun terjadi beberapa hambatan saat kegiatan berlangsung.

Uji keefektifan model layanan bimbingan kelompok berbasis Islami untuk meningkatkan kecerdasan sosial siswa SMK dianalisis dengan statistik non-parametrik melalui Independent Samples $T$ Test. Hasil perhitungan dengan menggunakan SPSS 21.00 sebagai berikut:

Tabel 3. Hasil Perhitungan Independent Samples T Test

\begin{tabular}{|c|c|c|c|c|c|}
\hline \multicolumn{6}{|c|}{ Group Statistics } \\
\hline & Kelompok & $\mathrm{N}$ & Mean & Std. Deviation & Std. Error Mean \\
\hline \multirow{2}{*}{ Hasil } & eksperimen & 10 & 14.7000 & 7.31893 & 2.31445 \\
\hline & Control & 10 & 1.7000 & 1.05935 & .33500 \\
\hline
\end{tabular}

Independent Samples Test

Levene's Test

for Equality of

t-test for Equality of Means

Variances 


\begin{tabular}{|c|c|c|c|c|c|c|c|c|c|c|}
\hline & & $\mathrm{F}$ & Sig. & $\mathrm{T}$ & Df & $\begin{array}{c}\text { Sig. } \\
(2- \\
\text { tailed } \\
)\end{array}$ & $\begin{array}{l}\text { Mean } \\
\text { Differ } \\
\text { ence }\end{array}$ & $\begin{array}{l}\text { Std. } \\
\text { Erro } \\
r \\
\text { Diff }\end{array}$ & $\begin{array}{r}95 \% \\
\text { Confide } \\
\text { Interval } \\
\text { Differe }\end{array}$ & $\begin{array}{l}\text { nce } \\
\text { of the } \\
\text { nce }\end{array}$ \\
\hline & & & & & & & & $\begin{array}{l}\text { eren } \\
\text { ce }\end{array}$ & Lower & $\begin{array}{l}\text { Upp } \\
\text { er }\end{array}$ \\
\hline \multirow{2}{*}{ hasil } & $\begin{array}{l}\text { Equal variances } \\
\text { assumed }\end{array}$ & \multirow[t]{2}{*}{10.994} & \multirow[t]{2}{*}{.004} & 5.559 & 18 & .000 & $\begin{array}{r}13.00 \\
000\end{array}$ & $\begin{array}{r}2.33 \\
857\end{array}$ & 8.08686 & $\begin{array}{r}17.9 \\
1314\end{array}$ \\
\hline & $\begin{array}{l}\text { Equal variances not } \\
\text { assumed }\end{array}$ & & & 5.559 & 9.377 & .000 & $\begin{array}{r}13.00 \\
000\end{array}$ & $\begin{array}{r}2.33 \\
857\end{array}$ & 7.74204 & $\begin{array}{r}18.2 \\
5796\end{array}$ \\
\hline
\end{tabular}

Pada output pertama yaitu Group Statistics dapat diinterpretasikan bahwa jumlah data/sampel (N) sebanyak 20 untuk masingmasing perlakuan, mean kelompok eksperimen adalah 14,7000 dan pada kelompok kontrol adalah 1,7000, nilai standard deviation kelompok eksperimen adalah 7,31893 dan kelompok kontrol adalah 1,05935, dan standard error of mean untuk kelompok eksperimen adalah 2,31445 sedangkan kelompok kontrol adalah 0,33500 . standard error of mean menggambarkan sebaran rata-rata sampel terhadap rata-rata dari keseluruhan kemungkinan sampel.

Pada output kedua yaitu Independent Samples Test, diperoleh hasil nilai t hitung lebih besar dari $\mathrm{t}$ tabel $(5,559>2,101)$ dan $\mathrm{P}$ value $(0,00<0,025)$ maka Ho (Hipotesis Nol) di tolak dan Ha (Hipotesis Alternatif) di terima sehingga dapat disimpulkan bahwa model bimbingan kelompok berbasis Islami terbukti efektif untuk meningkatkan kecerdasa sosial siswa SMK Roudlotus Saidiyyah Semarang.

Berdasarkan hasil analisis proses kegiatan pengembangan model bimbingan kelompok berbasis Ajaran Islam serta hasil yang telah dicapai oleh anggota kelompok membuktikan bahwa bimbingan kelompok berbasis Ajaran Islam efektif untuk meningkatkan kecerdasan sosial siswa SMK Roudlotus Saidiyyah Semarang. Indikasi keberhasilan dilihat dari peran yang dimiliki oleh pemimpin kelompok dan anggota kelompok pada setiap tahapan. Sedangkan untuk efektivitas layanan bimbingan kelompok dapat dibuktikan dari hasil perhitungan skala kecerdasan sosial yang menunjukkan adanya peningkatan hasil akhir pada skor total kecerdasan sosial.

Hal ini digambarkan Erdman (2008) yang berjudul Therapeutic Factors in Group Counseling: Implications for Audiologic Rehabilitation menyatakan bahwa bimbingan kelompok efektif dalam memberikan efek therapeutic pada individu karena dalam bimbingan kelompok memiliki asas yang universal dalam menghargai keberagaman dan kebersamaan dalam membahas sebuah topik penugasan serta mampu memberi dampak membangun harapan baru sesama anggota kelompok untuk menciptakan pemahaman dan pengetahuan baru sesama anggota kelompok yang tidak terbatas pada masalah pribadi melainkan juga masalah sosial, belajar, dan karier.

Bimbingan kelompok merupakan sarana yang bisa diakses oleh siswa untuk mendapatkan layanan dalam suasana kelompok yang dinamis. Kebutuhan akan bimbingan kelompok tampak semakin jelas mana kala para siswa mengalami kesulitan dalam bergaul atau mengaktualisasikan dirinya pada lingkungan sosial. Faktor-faktor yang menghambat tugas-tugas perkembangan siswa di bidang sosial diharapkan menjadi pekerjaan guru BK untuk mencari jalan keluar agar para siswa dapat menikmati kehidupan sosial yang layak. Solusi yang dimungkinkan untuk membantu siswa memecahkan masalah sosiologis adalah dengan memberikan layanan bimbingan kelompok yang berlandaskan pada pedoman beretika dalam agama. Layanan bimbingan kelompok yang dilaksanakan di SMK Roudlotus Saidiyyah Semarang belum menggunakan nilai-nilai yang terkandung di dalam ajaran Islam. Untuk membantu para bimbingan dan konseling, peneliti akan melakukan penelitian guna menemukan suatu model yang dapat memberikan formula untuk meningkatkan kecerdasan sosial.

Adapun nilai-nilai Ajaran Islam yang diintegrasikan di dalam pelaksanaan setiap tahap bimbingan kelompok ialah Ukhuwah Islamiyah (persaudaraan sesama muslim), Ta'awun (tolong menolong/bekerjasama), empati, keramahan, dan komunikasi dengan lemah lembut dan bahasa yang mudah dimengerti. Ajaran yang terkandung di dalam Islam berpotensi untuk menjadi modal sosial bagi aktivitas pengembangan diri siswa 
dalam bersosialisasi dan bermasyarakat. Dengan mengintegrasikan nilai nilai sosial yang terkandung dalam ajaran Islam ke dalam proses bimbingan kelompok untuk meningkatkan kecerdasan sosial siswa, diharapkan mampu menghasilkan siswa yang mempunyai keterampilan dan jiwa sosial yang baik berdasarkan sumber terpercaya yakni Al-Qur'an dan Hadits.

Hal ini sejalan dengan hasil penelitian yang dilakukan Plante. (2007) Integrating Spirituality and Psychotherapy: Ethical Issues and Principles to Consider. Peneliti mengadopsi hasil dari penelitian ini bahwa mengintegrasikan nilai-nilai spiritual ke dalam terapi sangatlah bermanfaat bagi klien. Hal ini dikarenakan sebagian besar penduduk dunia cenderung percaya terhadap agama. Pengintegrasian ini tentu sejalan dengan model yang akan dikembangkan oleh peneliti dengan memadukan nilai-nilai Islami dengan pelaksanaan bimbingan kelompok.

Rosmawati dkk dalam jurnalnya Relationship of Viewing Islamic Based Films With Pro-Social Personality among Teenaged Audience menyatakan bahwa film-film yang mengandung nilai-nilai Islam memiliki hubungan dan berkontribusi terhadap pengembangan kepribadian prososial. Hasil penelitian ini sudah diaplikasikan ke dalam kegiatan bimbingan kelompok berbasis Ajaran Islam dengan memutarkan film-film pendek yang bernuansa Islam di dalam kegiatan bimbingan kelompok. Kemudian Adam M. Grant and Francesca Gino. (2010) dalam jurnalnya yang berjudul A Little Thanks Goes a Long Way: Explaining Why Gratitude Expressions Motivate Prosocial Behavior menyatakan ucapan terima kasih dapat memotivasi perilaku prososial yang mengarah kepada merasa dihargai secara sosial. Hal ini berguna dalam pemberian perlakuan kepada anggota kelompok di dalam kegiatan bimbingan kelompok berbasis Ajaran Islam untuk meningkatkan kecerdasan sosial siswa.

\section{SIMPULAN DAN SARAN}

Bimbingan kelompok sudah dilaksanakan di SMK Swasta Kota Semarang dengan melewati empat tahapan, yakni tahap pembentukan, tahap peralihan, tahap kegiatan, dan tahap pengakhiran. Namun, dalam pelaksanaan yang dilakukan belum efektif dan belum memberikan hasil yang optimal. Masih ada beberapa kekurangan seperti kurangnya menggunakan media dan teknik, belum dilakukan analisis kebutuhan siswa dalam merekrut anggota kelompok, kurangnya persiapan sebelum melaksanakan bimbingan dan kelompok dan belum menggunakan pendekatan Islami.

Berdasarkan hasil pretest tingkat kecerdasan sosial siswa di SMK Roudlotus Saidiyyah Semarang tergolong tinggi secara keseluruhan, namun masih terdapat siswa yang termasuk kategori rendah dengan rincian kategori sangat tinggi $15 \%$, tinggi $38,33 \%$, rendah 46,67 dan sangat rendah $0 \%$. Rendahnya kecerdasan sosial ditunjukkan dengan masih ada siswa yang senang mengejek, berkelahi dan enggan membantu sesama. Oleh karena itu sangat penting menggunakan basis Islami dalam mengembangkan pelaksanaan bimbingan kelompok.

Telah dihasilkan model bimbingan kelompok berbasis ajaran Islam terdiri dari tujuh komponen, yakni (1) Rasional; (2) Visi dan Misi; (3) Tujuan; (4) Isi Model; (5) Pendukung Sistem Bimbingan Kelompok Berbasis Islami; (6) Tahapan Bimbingan Kelompok; (7) Evaluasi dan Tindak Lanjut. Kelayakan model tersebut sudah divalidasi oleh tiga pakar bimbingan dan konseling, serta sepuluh praktisi yaitu guru bimbingan dan konseling. Hasil uji kelayakaan menunjukkan bahwa model yang dirancang layak untuk diimplementasikan di lapangan.

Model bimbingan kelompok berbasis ajaran Islam efektif meningkatkan kecerdasan sosial. Uji keefektifan model dibuktikan melalui uji statistik Independent Samples Test, diperoleh hasil nilai $t$ hitung lebih besar dari t tabel $(5,559$ $>2,101)$ dan $\mathrm{P}$ value $(0,00<0,025)$ maka Ho (Hipotesis Nol) di tolak dan $\mathrm{Ha}$ (Hipotesis Alternatif) diterima sehingga dapat disimpulkan bahwa model bimbingan kelompok berbasis ajaran Islam terbukti efektif untuk meningkatkan kecerdasan sosial siswa SMK Roudlotus Saidiyyah Semarang. Persoalan mengenai rendahnya tingkat kecerdasan sosial siswa tidak hanya terjadi di SMK Roudlotus Saidiyyah Semarang, tetapi juga di sekolah dan daerah lainnya. Oleh karena itu bagi peneliti selanjutnya di sarankan agar mampu mengembangkan model bimbingan kelompok atau jenis bimbingan lainnya dengan memanfaatkan nilai-nilai yang terkandung di dalam ajaran Islam. 
Peneliti yang hendak melakukan kajian serupa mengenai bimbingan kelompok berbasis Ajaran Islam, hendaknya mampu mengkaji lebih dalam nilai-nilai Islam agar penelitian yang dilaksanakan lebih baik dan terhindar dari kesalahan dalam mengadopsi ajaran Islam.

\section{DAFTAR RUJUKAN}

Adam M. Grant dan Fransesca Gino. (2010). A Little Thanks Goes a Long Way: Explaining Why Gratitude Expressions Motivate Prosocial Behavior. Journal of Personality and Social. Vol. 98, No 6, hal. 946-955.

Amin, S.M. (2010). Bimbingan dan Konseling Islam. Jakarta: Amzah

Dahlan, Abdul Khaliq. (2009). Bimbingan dan Konseling Islami (Sejarah, konsep, dan Pendekatannya). Yogyakarta: Pura Pustaka

DetikNews. 04 Desember, (2013). Pelajar di Bogor Tewas Saat Tawuran. www.news.detik.com

Gibson, R.L. dan M.H. Mitchell. (2011). Bimbingan dan Konseling. Yogyakarta: Pustaka Pelajar. Diterjemahkan dari; Introduction to Counseling and Guidance.First publisher 2008 by Pearson Prentice Hall. Pearson education, Inc, Upper Saddle River, New Jersey

Prayitno. (2004). Pedoman Khusus Bimbingan dan Konseling. Jakarta: Depdiknas.

Rosmawati Mohamad Rasit, Md. Saleh $\mathrm{Hj}$. Hassan, Mohd. Nizam Osman dan Muhammad Sham Shahkat Ali. Relationship of Viewing Islamic Based Films With Pro-Social Personality among Teenaged Audience. Malaysian Journal of Communication. Jilid 28 (1): 107-120.

Erdman, Sue Ann. (2009). Therapeutic Factors in Group Counseling: Implications for Audiologic Rehabilitation. Perspectives on Aural Rehabilitation and Its Instrumentation. Vol. 16, 15-28.

Sutoyo, Anwar. (2009). Bimbingan dan Konseling Islami (Teori dan Praktik). Yogyakarta: Pustaka Pelajar.

Suyono, H. (2007). Social Intellegence. Yogyakarta: Ar Ruzz Media.

Plante. G.T (2007). Integrating Spirituality and Psychotherapy: Ethical Issues and Principles to Consider. Journal of Clinical Psychology. Vol. 63 (9), 891902.

Wibowo, M.E. (2005). Konseling Kelompok Perkembangan. Semarang. UNNES PRESS. 